\title{
A Survey on One Health Perception and Experiences in Europe and Neighboring Areas
}

\begin{abstract}
Francesco Chiesa ${ }^{1 \dagger}$, Laura Tomassone ${ }^{1+}$, Sara Savic ${ }^{2}$, Alessandro Bellato ${ }^{1}$, Andrei Daniel Mihalca ${ }^{3}$, David Modry ${ }^{4,5,6}$, Barbara Häsler ${ }^{7}$ and Daniele De Meneghi ${ }^{1 *}$

'Department of Veterinary Science, University of Turin, Grugliasco-Turin, Italy, ${ }^{2}$ Scientific Veterinary Institute "Novi Sad", Novi Sad, Serbia, ${ }^{3}$ Faculty of Veterinary Medicine, University of Agricultural Sciences and Veterinary Medicine of Cluj-Napoca, Cluj Napoca, Romania, ${ }^{4}$ Department of Botany and Zoology, Faculty of Science, Masaryk University, Brno, Czechia, ${ }^{5}$ Institute of Parasitology, Biology Centre, Czech Academy of Sciences, Ceske Budejovice, Czechia, ${ }^{6}$ Department of Veterinary Sciences, Faculty of Agrobiology, Food and Natural Resources/CINeZ, Czech University of Life Sciences Prague, Prague, Czechia,

${ }^{7}$ Royal Veterinary College, London, United Kingdom
\end{abstract}

A questionnaire survey was promoted under the COST Actions "Network for Evaluation of One Health-NEOH" and "European Network for Neglected Vectors and VectorBorne Infections-EURNEGVEC", from June 2016 to April 2017, to collect information on the existence of One Health $(\mathrm{OH})$ collaboration and implementation of $\mathrm{OH}$ initiatives in $37 \mathrm{EU}$ COST Countries. The questionnaire was to be answered by key respondents representing the three major $\mathrm{OH}$ components: (i). Animal Health; (ii). Human Health/Public Health; (iii). Environmental Health. A target respondent rate of nine respondents/country was aimed for, representing the following categories: (i). ministries; (ii). academia-research; (iii). private sector and NGOs, associations and scientific societies. The questionnaire, composed of 27 questions organized in six sections, was circulated to target respondents by Committee Members of the two COST actions. A total of 171 respondents from 34 countries completed the questionnaire, mainly belonging to academic and research institutions (55.5\%), and to Animal Health/Animal Science fields (53.8\%). Although the majority (57.9\%) declared they had heard about $\mathrm{OH}$, few respondents (10.7\%) provided a complete definition. The "human" and "animal" elements prevailed over other key elements of $\mathrm{OH}$ definition (ecosystem, intersectoral, transdisciplinary, holistic, collaboration). Overall, $62.6 \%$ respondents declared to take part in $\mathrm{OH}$ initiatives. Antimicrobial resistance, avian influenza and environmental pollution were cited as the top three $\mathrm{OH}$ issues over the past 5 years. Limitations and gaps in intersectoral collaboration included communication and organizational problems resulting in poor networking, differing priorities and a lack of understanding between sectors. Regarding control and monitoring of zoonotic diseases, respondents from different sectors preferentially selected their own directorates/ministries while actually in most countries both Ministry of Health and Ministry of Agriculture are engaged. According to respondents, the level of awareness of $\mathrm{OH}$ amongst the general public is limited. Similarly, a dearth of opportunities of collaborations at different institutional and/or professional levels was described. Our survey provided an overview of how respondents in COST countries perceived and experienced $\mathrm{OH}$ and current limits to $\mathrm{OH}$ implementation. Identifying how initiatives are 
currently working and knowing the promoting and hindering factors allowed suggesting strategies to promote efficiency and effectiveness of $\mathrm{OH}$ implementation in the future.

Keywords: questionnaire survey, One Health, EU COST countries, intersectoral collaboration, interdisciplinary/multidisciplinary, $\mathrm{OH}$ strategies and policies

\section{INTRODUCTION}

The collaboration between human, animal and environmental health sectors is considered crucial; a need highlighted by recent financial, economic, social, environmental and health crises. The complexity of health determinants, makes it difficult for single disciplines and institutions to deal with all health problems and challenges related to animal, public and environmental health $(1,2)$.

Changes in land use, habitat fragmentation, ecosystem invasion, direct and indirect interactions between animal species, including ourselves, have increased, and this has led to changes to ecological or biological systems. This fact has greatly contributed to the emergence of zoonotic pathogens: changes in patterns of contact between wild and domestic animals (e.g., Nipah virus), direct human and wild animal contact (e.g., HIV, Ebola), and changes in species abundance or diversity (e.g., Hantavirus, Lyme disease) (3). New pathogens might have the capacity for inter-human spread and even pandemic potential among humans, as observed in the current COVID-19 global emergency. Outbreaks of highly infectious diseases, including zoonoses, but also antibiotic resistance, interrelated obesity in humans and pets, food security and food safety, problems related to growing urbanization, lack of green spaces in the cities, uncontrolled environmental pollution and biodiversity loss, are only few examples where an integrated approach to health, such as One Health $(\mathrm{OH})$, can be effectively employed $(1,2)$. Not only "classical zoonoses" can be tackled using a $\mathrm{OH}$ approach, but also other hazards occurring at the human, animal, ecosystem interface, such as exposure to toxicants through the environment and foods of animal origin. Some authors even advocate this new perspective as "toxicant-related zoonoses" highlighting the importance of new food safety issues within the environmentfeed-food chain (4). Also, climate change adds uncertainty and contributes to health crises, affecting biological systems through various mechanisms, such as modifying the lifecycle of vectors, host species and pathogens, disrupting the synchrony among species, destructing habitats, etc. (5). Since species experience environmental changes differently, the expertise from veterinary, environmental and public health professionals are needed to understand ecological interactions and to forecast plausible reactions. The integration of expertise from environmental and life sciences can help to deepen knowledge and to understand each aspect of an issue, combining different perspectives (6).

In Europe, but also elsewhere, the degree and quality of collaboration amongst various health disciplines and institutions varies substantially. Integrated approaches to health are challenging because they require complex systems of communication and collaboration that are difficult to delimit (1). Despite the above-mentioned difficulties, in many European countries, a large number of integrated health initiatives has been implemented, some of them described or reported as "One Health." Several studies investigated $\mathrm{OH}$ characteristics, provided proof of concept, demonstrated its added value, or established how to evaluate $\mathrm{OH}$ initiatives (7-14). Moreover, the World Bank published guidance on how to operationalize $\mathrm{OH}$ (15). Similarly, national action plans to combat AMR are encouraged to use $\mathrm{OH}$ principles (16). These efforts have generated momentum in $\mathrm{OH}$ and led to many different initiatives worldwide. A study looking at $\mathrm{OH}$ networks globally found a multitude of different networks, but generally a lack of direction and institutionalization (17). There is currently no register in Europe that would allow gaining a systematic understanding of the $\mathrm{OH}$ landscape in Europe.

In order to explore existing collaboration amongst the animal health, human/public health, environmental health and sectors, and to collect information on the existence and implementation of $\mathrm{OH}$ actions and initiatives in EU countries, a questionnaire-based survey was designed and circulated amongst EU COST Member Countries, associated and near-neighbor countries (https://www.cost.eu); there were 37 countries at the time the survey was initiated. The questionnaire was designed and promoted under the initiatives of the COST Actions TD1404 "Network for Evaluation of One Health-NEOH” (http://neoh.onehealthglobal.net) and TD1303 "European Network for Neglected Vectors and Vector-Borne Infections-EURNEGVEC” (https://www.eurnegvec.org).

\section{MATERIALS AND METHODS}

The questionnaire was developed in Google forms and structured in six sections: (1). general information; (2). about "One Health"; (3). zoonotic diseases, environmental health and AMR: examples of "burning" $\mathrm{OH}$ issues/initiatives; (4). aspects limiting interdisciplinarity and intersectorality in $\mathrm{OH}$; (5). conclusions; (6). end of questionnaire (including comments, remarks and/or suggestions).

The survey consisted of 27 questions addressing the above mentioned objectives (i.e., to explore the existing collaboration amongst animal health, human/public health, environmental health sectors, to collect information on the existence and implementation of $\mathrm{OH}$ actions and initiatives in EU COST countries). Twenty-one were closed-ended questions, of which six in Likert-scale format, and six were open-ended questions. An informed consent form was provided at the beginning of the questionnaire where respondents were advised that the questionnaire was anonymous and that, by completing and submitting it, they voluntarily agreed to participate. Assurance of privacy and confidentiality is highly valued in e-mail 
questionnaire surveys, as reported by Saleh and Bista (18). Ethical approval was sought and granted by the Clinical Research and Ethical Review Board at the Royal Veterinary College, grant holder of COST Action TD1404 NEOH (ref. n. URN 2016 1554). Respondents were to be contacted by the Management Committee (MC) members and MC substitutes of the two COST Actions in each country. Key respondents were meant to represent the three components of $\mathrm{OH}$ (animal health, human health/public health and environmental health). MC members and MC substitutes contacted by email the target institutions through the official institutional contact email address, providing the link to the online questionnaire, and explaining to potential respondents the scope and the importance of the survey. Where deemed necessary, the COST Action members translated the message to their local language before reaching out to their contacts in the different institutions.

We expected nine respondents per country, one for each $\mathrm{OH}$ component, per each one of the following categories:

i. Public institutions/ministries, that is, the Directors/Heads of Veterinary Services, Ministry of Agriculture (MoA), Ministry of Health (MoH); Directors/Heads of Human Health \& Public Health Services, MoH; Environmental Health Services, Ministry of Environment or other applicable Ministries/Directorates, according to the national organization/system of each COST countries;

ii. Academia/research (i.e., Deans/Directors of the Schools/Universities and of National Research Centers on Veterinary Medicine, Human Medicine and Public Health, and Environmental/Earth Sciences, under Ministry of Education;

iii. Private sector (i.e., presidents of the National Boards/Colleges of Veterinarians, Medical Surgeons \& Public Health doctors, and Environmental Earth Sciences doctors.

In addition, NGOs, associations, scientific societies involved in $\mathrm{OH}$ initiatives and activities were asked to participate in the survey.

The overall expected respondents were 333 (three respondents representing human, animal and environmental health each from at least three of the four categories listed per 37 COST countries).

The questionnaire was accessible for 10 months (June 2016April 2017); it was subsequently closed, and the data collected were downloaded. Answers were checked for consistency, cleaned for analysis and the questionnaire was removed from the hosting platform.

A blank version of the questionnaire (.pdf) is available in the Supplementary Material.

Data were analyzed with R software (19). We computed descriptive statistics of questions answers and scores. In order to analyze qualitative data, open answers were categorized into classes. Non-parametric tests (Wilcoxon test and Kruskal-Wallis rank sum test) were used to detect significant differences in scores among categorical variables; Chi-square and Fisher Exact tests were employed to evaluate associations among categorical variables. For all statistical tests, a two-tailed significance level of $\alpha=0.05$ was adopted.
As regards the "definition of One Health" (question in section 2 ), answers were analyzed in order to detect five key words categories in the definition given by respondents, and a score was attributed, being five the maximum (all key words and key word categories included in the definition). The five key words were human health, environmental health, animal health, intersectoral/transdisciplinary/holistic, collaboration/sharing, as described in literature $(2,20)$. Advantages of $\mathrm{OH}$, which respondents were asked to score (question in section 2), are described in Häsler et al. (21).

Interviewees were asked to select health hazards (mainly zoonotic diseases) that are controlled and monitored by the Ministry of Health and/or Agriculture (question in section 3 ); the list of major health hazards/zoonoses was taken from the Public Health England website (https://www.gov.uk/ government/publications/list-of-zoonotic-diseases/list-of-

zoonotic-diseases).

In section 4 , interviewees were asked to score the level and opportunities for $\mathrm{OH}$ collaborations in their countries at different institutional and/or professional levels, choosing among: "poor," "fair," "good," "excellent," and "n/a": not applicable.

\section{RESULTS}

Overall, 171 key respondents from 34 countries answered the questionnaire with at least one respondent per country.

Few countries -namely Belgium, Bosnia \& Herzegovina, Hungary, Italy, The Netherlands, and Portugal- reached or even exceeded, the expected minimum number of questionnaires answered ( $n=9 /$ country), other countries reached or slightly exceeded six questionnaires answered (Austria, Czech Republic, Lithuania, Serbia and Switzerland), while the remaining others answered less. No responses were received from Iceland, Montenegro, and Cyprus. The number of respondents by country is shown in Figure 1.

Results are reported by questionnaire section.

\section{Questionnaire Section 1-General Information}

The majority of respondents declared to have training or a professional background in Animal Health or Animal Sciences ( $n=92 ; 53.8 \%)$, followed by Public Health or Human Health ( $n=51 ; 29.8 \%)$. Those having a professional background in Environmental Sciences and Life Sciences (including biologists, chemists and basic science disciplines) were respectively 12 (9.3\%) and 5 (2.9\%). Five respondents $(2.9 \%)$ had a professional background in Food Safety, while two respondents were trained outside the "traditional" health disciplines, one of them in Sociology (0.6\%) and the other one in Engineering (0.6\%).

Most respondents worked at Higher Education Institutions/Universities ( $n=66 ; 38.6 \%)$ and Research Centers $(n$ $=29 ; 17.0 \%)$, followed by Governmental Institutions/Ministries ( $n=44 ; 25.7 \%$ ). Those working in the private sector and NGOs were $14(8.2 \%)$ and $9(5.3 \%)$, respectively. Two respondents were 


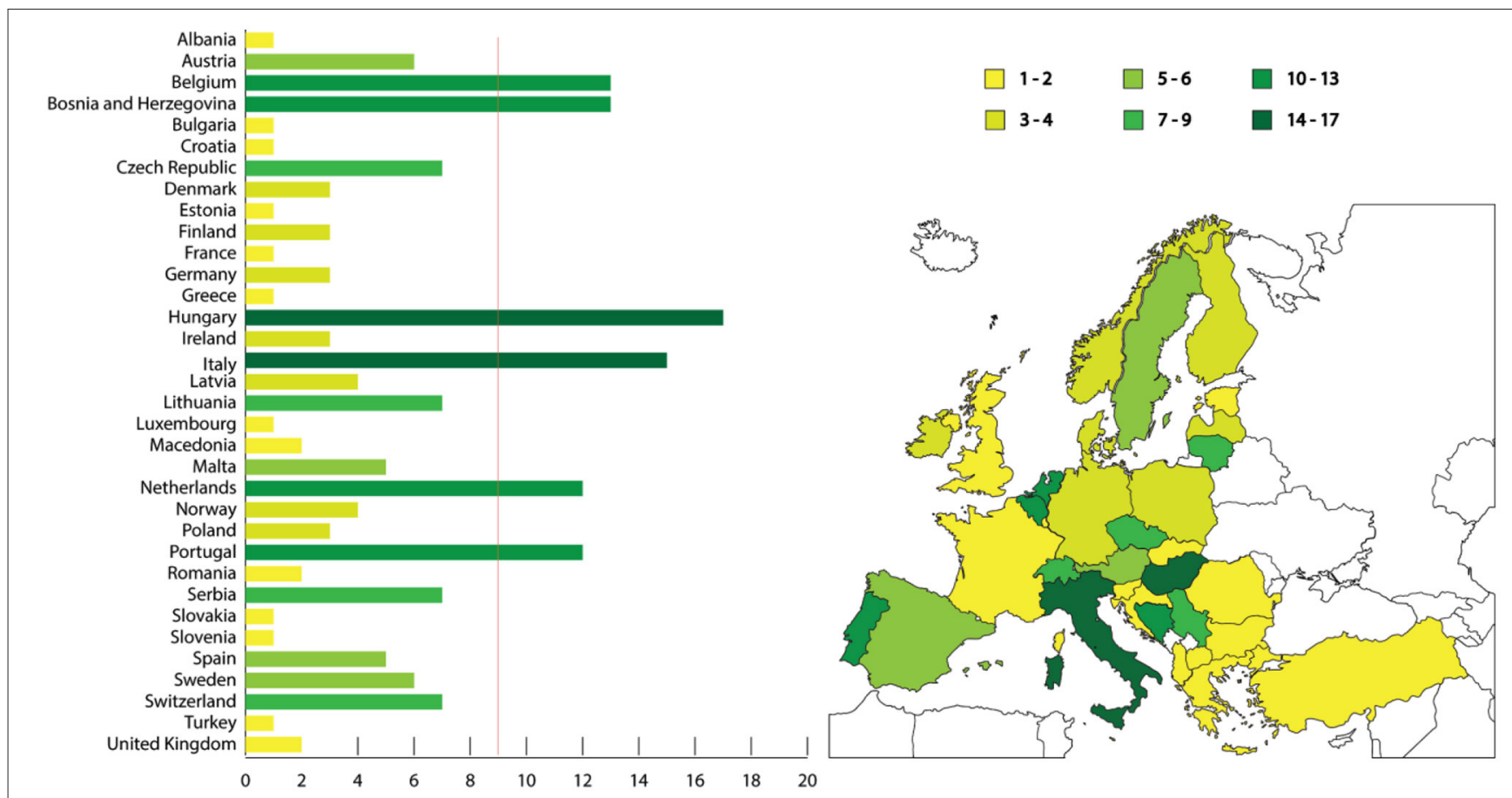

FIGURE 1 | Map illustrating the number of respondents to the questionnaire per country, and bar chart with the number of questionnaires answered considering the number of expected respondents (red line). Colors grade from yellow (low number of questionnaires answered) to dark green (high number).

employed in International Organizations, and seven respondents did not give details.

The above-mentioned institutions work on Animal Health ( $n$ $=77 ; 45.0 \%)$, Public Health $(n=50 ; 29.2 \%)$, Human Health $(n=23 ; 13.4 \%)$ and Environmental Health $(n=17 ; 9.9 \%)$. Four respondents did not provide enough details to attribute the discipline of the institution to any of the above categories (hence aggregated under "Other") (Figure 2).

Most of the respondents stated to be heads/directors $(n=$ $57 ; 33.9 \%)$, professors $(n=44 ; 26.1 \%)$ and researchers $(n=18$; $10.7 \%)$. Thirteen were officers $(7.7 \%)$ and another 13 respondents were consultants $(7.7 \%)$. The remaining respondents detailed their positions as medical doctors $(n=5 ; 2.9 \%), \mathrm{PhD}$ students $(n=5 ; 2.9 \%)$, epidemiologists $(n=4 ; 2.3 \%)$ and vet clinicians $(n=3 ; 1.7 \%)$. Six persons $(3.5 \%)$ did not answer.

\section{Questionnaire Section 2-About one health}

Ninety-nine respondents (57.9\%) declared they had heard about One Health, while 36 (21.1\%) declared that they had never heard about it; 36 people did not respond to the question.

Respondents were asked to define $\mathrm{OH}$ in one sentence. Amongst the 149 answers (87.1\% of respondents), only $16(10.7 \%)$ were considered to be a "complete definition." The "human" component was mentioned by 129 respondents (86.6\%), the "animal" component by $110(73.8 \%)$, and the "environmental" one by $63(42.3 \%)$. Fifty-nine respondents $(39.6 \%)$ included a term among "intersectoral/transdisciplinary/holistic" in the definition, and 34 named "collaboration/sharing" (22.8\%).

Considering the disciplinary background of respondents, the best median score for the $\mathrm{OH}$ definition (one point for each element) was obtained by "Life Sciences" respondents (3.5, Q1-Q3: 3.25-3.75), followed by "Human Health" respondents (3; Q1-Q3: 3-3). The median score of the other categories (excluding the two respondents with a disciplinary background in Sociology and Engineering, who did not answer) was two. However, the difference in median scores among different disciplinary backgrounds was not significant (Kruskal Wallis rank sum test, $p=0.08$ ).

When interviewees were asked if they were currently involved in $\mathrm{OH}$ initiatives, the large majority stated to be involved $(n=$ $107 ; 62.6 \%$ ), while 64 respondents stated that were not. Most people involved had a background in "Animal Sciences" $(n=$ 70, 65.4\%), followed by "Public Health" $(n=16,15.0 \%)$ and "Human Health" ( $n=12,11.2 \%)$. The involvement significantly differed among disciplinary backgrounds (Fisher Exact test, $p<$ 0.01 ), with $76.1 \%$ of the "Animal Sciences" respondents being involved, vs. 55.2\% of "Public Health", 54.5\% of "Human Health," $40 \%$ of "Food Safety," $37.5 \%$ of "Environmental Sciences" and $20 \%$ of "Life Sciences." The two respondents with background in Sociology and Engineering declared not to be involved in $\mathrm{OH}$ initiatives.

The interviewees were also asked to briefly describe the $\mathrm{OH}$ initiatives. Since this was an open answer, it was categorized in: zoonoses (54 answers, 50.4\%); $\mathrm{OH}$ in general (i.e., a broad comprehensive category that includes activities or initiatives 


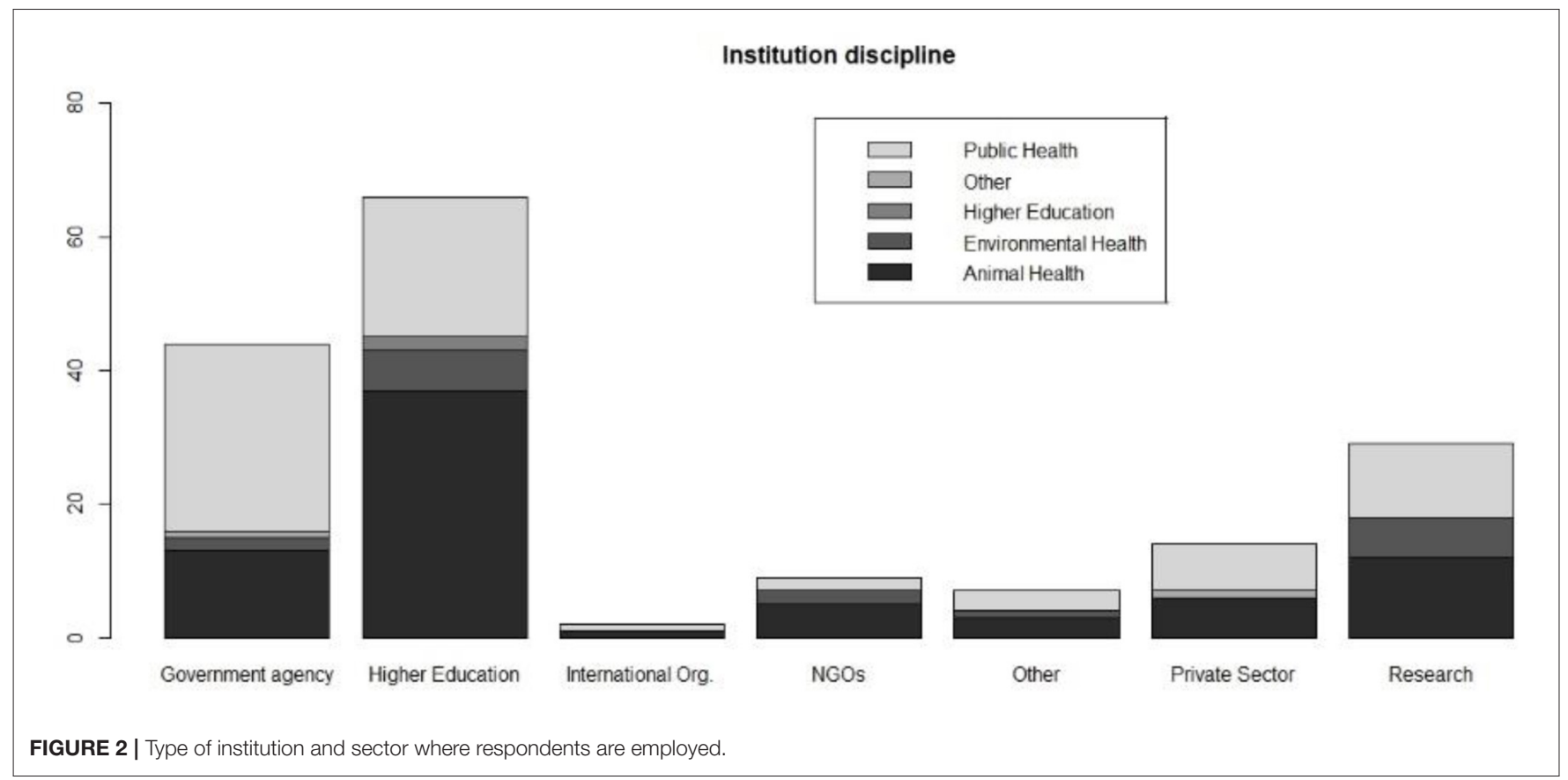

having the scope to promote intersectoral working spaces) ( $n$ $=12,11.2 \%)$; food hygiene $(n=11,10.2 \%)$; antimicrobial resistance (AMR) $(n=9,8.4 \%)$; education $(n=5,4.6 \%)$; animal health $(n=3,2.8 \%)$; human health $(n=2,1.8 \%)$; AMR and zoonoses, and AMR and food hygiene (one answer each, $0.9 \%$ ). Nine interviewees did not specify the characteristics of the $\mathrm{OH}$ initiatives they were involved in. $\mathrm{OH}$ initiatives on zoonoses were mostly cited by people with a background in "Animal Sciences" ( $n$ $=36)$, followed by "Public Health" $(n=8)$ and "Human Health" $(n=6)$. "Environmental Health" respondents were involved in initiatives on zoonoses $(n=3), \mathrm{OH}$ in general $(n=2)$ and food safety $(n=1)$. Education activities were cited by "Animal Sciences" respondents only $(n=5)$.

Sixty-one respondents stated that $\mathrm{OH}$ had been officially endorsed by their respective Institutions, while 51 Institutions did not endorse; 59 respondents did not answer. No differences in endorsing or not $\mathrm{OH}$ initiatives were found among institution types (Fisher Exact Test, $p=0.7$ ) (Figure 3). The institutions reportedly endorsed $\mathrm{OH}$ by implementing initiatives regarding education $(n=16), \mathrm{OH}$ in general $(n=16)$, animal health $(n=7)$, zoonoses $(n=5)$, AMR, human health, and food safety ( $n=2$ each). Less than half $(47.7 \%)$ of respondents involved in $\mathrm{OH}$ initiatives worked in institutions that officially endorsed $\mathrm{OH}$.

The respondents quoted various examples of programs for which a $\mathrm{OH}$ approach was adopted in their institutions. These examples mostly referred to zoonoses surveillance and control $(n=24)$, health education $(n=20)$, AMR $(n=17)$ and food hygiene $(n=15)$. Other cited examples were research $(n=9)$, animal health $(n=7)$, brucellosis and $\mathrm{OH}$ in general $(n=5)$, vector-borne diseases $(n=4)$, drawing/writing legislation $(n=4)$, rabies, salmonella, WNV $(n=3$ each),
Campylobacter, Q Fever, HPAI, info sharing and preventive medicine ( $n=2$ each). Air quality, climate change, risk analysis, drinking water quality, human health, mastitis, leishmaniasis, leptospirosis, Lyme disease, rodent-borne diseases, tuberculosis, toxoplasmosis, TSE, and tularemia were cited once.

When asked to score -from 1 (low) to 5 (high)- some advantages of $\mathrm{OH}$ described in literature, "Early detection of threat and timely, effective or rapid response" was considered the major advantage (median score: 5.0 ), followed by "Better/improved/more effective disease control and/or biosecurity measures" (4.5), thus suggesting that respondents attributed the greatest importance to preventative measures. A lower score was given to "Economic benefit/increase in economic efficiency" (4.0), "Improvement in human or animal health or well-being" (4.0), "Higher quality or larger quantity of information and data and improved knowledge or skills" (4.0), "Ecosystem benefit" (4.0'), "Design of health policies" (4.0) and "Personal or social benefits" (3.0) (Figure 4).

When asked about the existence of boards/ committees/associations actively dealing with $\mathrm{OH}$ issues/initiatives in their country, 69 respondents answered affirmatively, while 15 stated "no." Some respondents provided details, stating that such boards mainly deal with AMR, zoonoses, food hygiene, vector-borne diseases and outbreak management.

One hundred fourteen $(66.7 \%)$ respondents declared that, in their countries, there are formal connections between veterinary/animal health and public health administrations (governmental institutions or services). Conversely, 55 respondents answered "no"; two answers were missing. The answer significantly differed among respondents with different disciplinary backgrounds (Fisher Exact test, $p=0.01$ ). The highest "yes" frequency was registered among Food Safety people 

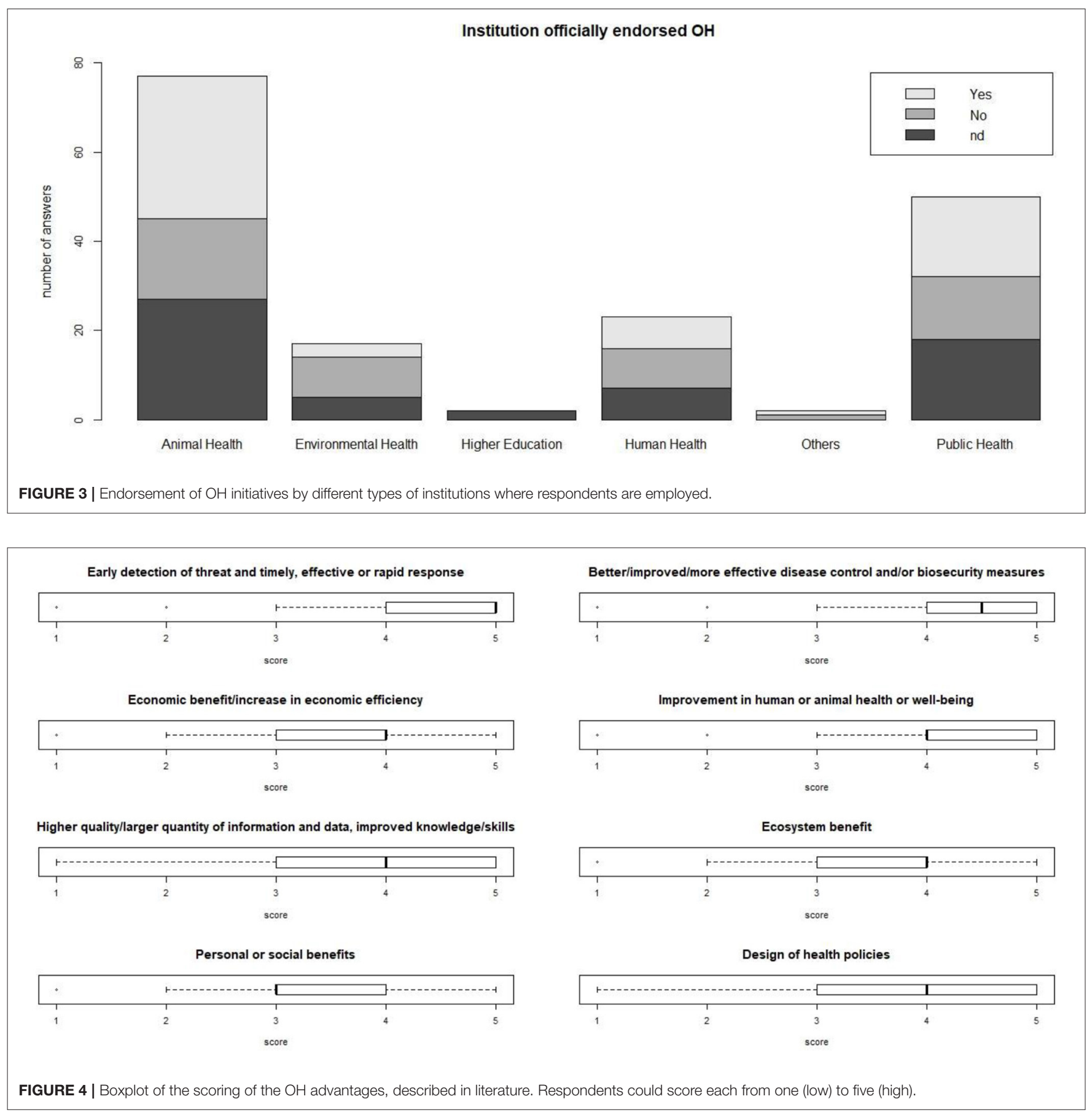

(all five respondents), Public Health (86.2\%), Animal Sciences (69.2\%), Human Health (57.1\%). "No" answers prevailed among Environmental Sciences (43.8\%) and Life Sciences (40\%) people, and were given by the two respondents with disciplinary background in Sociology and Engineering.

The respondents were then asked to answer a subset of questions on the level, nature and duration of such cooperation. Most connections were reported to be at national level ( $n=72$ answers, 63.2\%), but some respondents indicated national-subnational and local $(n=20)$, national and subnational $(n=14)$, and national and local $(n=3)$ formal connections. Subnational, that is, regional, provincial $(n=7)$, local $(n=2)$ and subnational-local $(n=1)$ connections were also cited. The nature of the cooperation mainly referred to exchange of data $(n=93)$, joint surveillance $(n=69)$, health policies $(n=61)$, joint intervention $(n=51)$, joint preparedness $(n=$ $44)$, joint training $(n=41)$, shared budget $(n=9)$. As regards the length of the cooperation, it ranged from "the last 5 years" 
( $n=23)$, to "the last 5 -to-10 years" $(n=30)$, "10-to-20 years" ( $n$ $=27)$, "20-to-30 years" $(n=6)$ and to "more than 30 years" $(n=$ 15). This last answer was given by respondents of the following countries: Italy (five respondents), Malta and Hungary ( $n=$ 2 each), and Belgium, Bosnia-Herzegovina, Denmark, Latvia, Poland, Romania ( $n=1$ each).

Ninety respondents (52.6\%) stated they were aware of $\mathrm{OH}$ initiatives being implemented in their countries; 14 respondents (8.2\%) answered "no" and the others did not answer. According to the respondents, the number of initiatives being implemented varied from 1 to $5(n=54)$, from 6 to $10(n=16)$, and more than $10(n=12)$. The fields of activities concerning these initiatives were: disease surveillance and monitoring $(n=80)$; disease prevention and control $(n=74)$; research $(n=70)$; participants awareness on the programs $(n=50)$; higher education programs $(n=41)$; NEOH and "Knowledge sharing platforms" were cited by one respondent each.

As regards the categories of professionals involved in these initiatives, the following were cited: veterinarians $(n=138)$; medical doctors $(n=119)$; biologists/entomologists $(n=$ $82)$; environmental/ ecosystem specialists/ecologists $(n=70)$; chemists $(n=23)$; sociology/anthropology/gender specialists $(n$ $=15)$; pediatricians $(n=15)$; family doctors $(n=13)$. Other professionals, entered by respondents, were: public health officers $(n=3)$; microbiologists, epidemiologists $(n=2$ each). Food safety specialists, earth scientists, economists, psychologists, pharmacologists, civil servants/scientific experts, policy risk managers were also quoted.

\section{Questionnaire Section 3-Zoonotic Diseases, Environmental Health and AMR: Examples of "Burning" OH Issues/Initiatives}

Ninety-six people ( $82.1 \%$ of the 117 that answered this question) stated that, in their countries, there is an existing and active cooperation between the Ministry of Health and the Ministry responsible for Animal Health, when dealing with zoonoses. They also stated that there is an obligation to guarantee a reciprocal flux of information or data between Public Health and Veterinary Services. Interviewees were asked to select which zoonotic diseases are controlled and monitored by the Ministry of Health $(\mathrm{MoH})$ and/or Agriculture (MoA). Results are illustrated in Table 1.

A couple of questions referred to environmental toxicants. When interviewees were asked about the "level of awareness by the public on zoonoses caused by exposure to environmental toxicants," scoring from 1 (poor) to five (excellent), the median score attributed by 136 respondents was 2 (Q1-Q3: 2-3). Fiftynine persons stated they were not competent in the field. The median score given to the "quality of national plans for the prevention and monitoring of toxicant zoonoses" was 3 (Q1-Q3: $2-4)$. In this case, 85 respondents answered the question, while 88 people stated they were not competent in the field.

According to 83 respondents $(48.5 \%)$, their respective countries contribute to the AMR surveillance in Europe, with specific monitoring and research programs. Conversely, 85
TABLE 1 | Zoonotic diseases controlled and monitored by the Ministry of Health $(\mathrm{MoH})$ and/or Agriculture (MoA), according to respondents.

\begin{tabular}{llll}
\hline Zoonosis & MoA (n; \%) & MoH (n; \%) & MoH + MoA (n; \%) \\
\hline Anthrax & $31(26.5 \%)$ & $33(28.2 \%)$ & $53(45.3 \%)$ \\
Avian influenza & $40(31.0 \%)$ & $27(20.9 \%)$ & $62(48.0 \%)$ \\
Brucellosis & $40(32.2 \%)$ & $22(17.7 \%)$ & $62(50.0 \%)$ \\
Campylobacteriosis & $22(19.4 \%)$ & $39(34.5 \%)$ & $52(46.0 \%)$ \\
Cysticercosis/taeniasis & $39(39.0 \%)$ & $26(26.0 \%)$ & $35(35.0 \%)$ \\
Ebola & $0(0 \%)$ & $84(82.3 \%)$ & $18(17.6 \%)$ \\
Leptospirosis & $22(20.7 \%)$ & $35(33.0 \%)$ & $49(46.2 \%)$ \\
Plague & $6(7.3 \%)$ & $49(59.7 \%)$ & $27(32.9 \%)$ \\
Q Fever & $28(26.6 \%)$ & $26(24.7 \%)$ & $51(48.5 \%)$ \\
Rabies & $31(25.6 \%)$ & $27(22.3 \%)$ & $63(52.0 \%)$ \\
RVF & $19(25.6 \%)$ & $26(35.1 \%)$ & $29(39.1 \%)$ \\
Ringworm & $17(25.3 \%)$ & $26(38.8 \%)$ & $24(35.8 \%)$ \\
Salmonellosis & $11(8.6 \%)$ & $35(27.5 \%)$ & $81(63.7 \%)$ \\
Toxoplasmosis & $15(14.7 \%)$ & $38(37.2 \%)$ & $49(48.0 \%)$ \\
Trichinellosis & $35(29.6 \%)$ & $26(22.0 \%)$ & $57(48.3 \%)$ \\
Tularemia & $19(19.5 \%)$ & $28(28.8 \%)$ & $50(51.5 \%)$ \\
\hline
\end{tabular}

people answered "no answer/I don't know." Conflicting answers within the same country were registered, with eight respondents stating that their respective countries did not contribute to the EU AMR monitoring, although other respondents from the same countries stated they do contribute (Figure 5).

\section{Questionnaire Section 4-Aspects Limiting Interdisciplinarity/Intersectorality in $\mathrm{OH}$}

A "siloed approach" of disciplines was considered a limit for interdisciplinarity and intersectorality by $18.1 \%$ of respondents $(n=31)$ working in $\mathrm{OH}$, followed by "lack of resources" (15.8\% of respondents, $n=27)$, institutional $(10.5 \%, n=18)$ and "education limits" $(8.2 \%, n=14)$. Some people mentioned more than one limit. Two respondents stated that there are no limiting factors $(1.2 \%)$.

Table 2 describes the level(s) and the opportunities for $\mathrm{OH}$ collaborations, according to the interviewees, within professional boards, University Departments, institutions involved in veterinary surveillance and food security, and institutions involved in emergencies management.

\section{Questionnaire Section 5-Conclusions}

Respondents were asked to rate how well the $\mathrm{OH}$ approach is implemented by the professionals employed/engaged in Veterinary, Public and Environmental Health sectors in their country, scoring from 1 (poor) to 5 (excellent). The median score attributed by 130 respondents was three (Q1-Q3: 2-3). Details of the answers aggregated by countries are illustrated in Figure 6.

The existence of recent formal initiatives to establish and/or to strengthen intersectoral collaboration, aimed at global advocacy of $\mathrm{OH}$ approach, was confirmed by 49 respondents $(29.8 \%)$. Seventeen (10.3\%) answered "no" and the other interviewed selected "no answer/I don't know." 


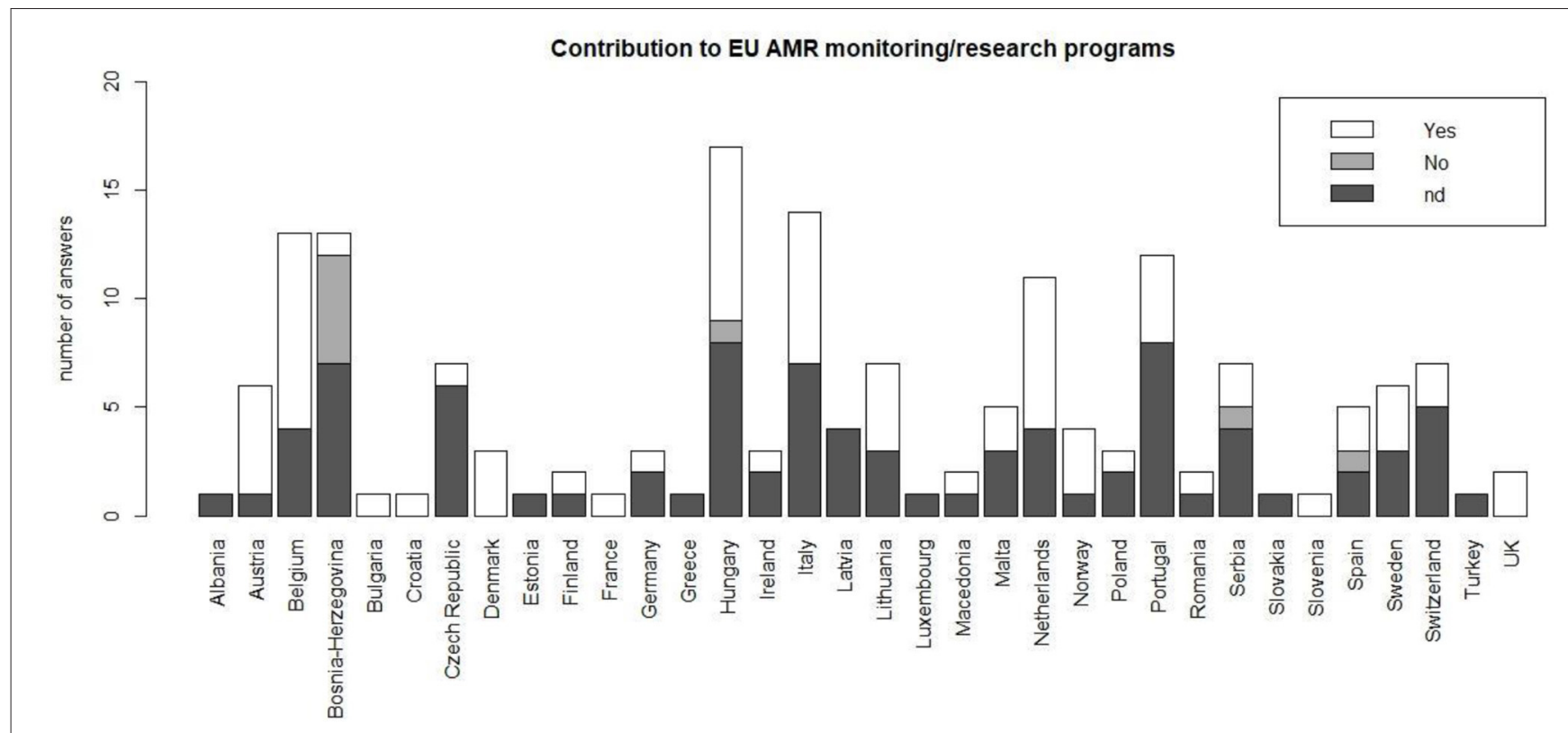

FIGURE 5 | Contribution of respondents' countries to European programs for the monitoring of AMR; nd = not determined/answer not known.

TABLE 2 | Level and opportunities for OH collaboration at different institutional and/or professional levels.

\begin{tabular}{|c|c|c|c|c|c|}
\hline $\begin{array}{l}\text { Level and opportunities } \\
\text { for OH collaboration } \\
\text { within }\end{array}$ & Poor (\%) & Fair (\%) & Good (\%) & Excellent (\%) & n/a (\%) \\
\hline Professional boards & $40(26.1 \%)$ & 35 (22.9\%) & $54(35.3 \%)$ & $8(5.2 \%)$ & $16(10.5 \%)$ \\
\hline University Departments & 37 (24.3\%) & 47 (30.9\%) & 47 (30.9\%) & $10(6.6 \%)$ & $11(7.2 \%)$ \\
\hline $\begin{array}{l}\text { Institutions involved in vet } \\
\text { surveillance and food } \\
\text { security }\end{array}$ & 18 (11.9\%) & $46(30.5 \%)$ & 64 (42.4\%) & $13(8.6 \%)$ & $10(11.9 \%)$ \\
\hline $\begin{array}{l}\text { Institutions involved in } \\
\text { emergencies } \\
\text { management }\end{array}$ & $22(14.5 \%)$ & $43(28.3 \%)$ & $64(42.1 \%)$ & $11(7.2 \%)$ & $12(7.9 \%)$ \\
\hline Total & 117 & 171 & 229 & 42 & 49 \\
\hline
\end{tabular}

When asked to cite the top three environmental, animal and human health issues in their country over the past 5 years, most respondents cited AMR ( $n=44$ respondents; $25.7 \%)$, avian influenza $(n=32 ; 18.7 \%)$ and environmental pollution $(n=27$; $15.8 \%)$. A Sankey diagram shows all answers by regional areas (Figure 7). When considering answers by group of countries in the same geographical region, we observed differences in the top three issues (Figure 8): AMR was cited in all regions except from Balkan countries, avian influenza in all regions except from Balkan and Scandinavian/Baltic countries, and all except Eastern European countries cited environmental pollution.

Strictly related to section 4 , respondents were asked to answer where and what are the gaps in $\mathrm{OH}$ schemes. Answers mostly referred to the approach of institutions $(n=24)$, followed by problems of funding $(n=12)$ and communication $(n=11)$, the siloed approach of disciplines $(n=11)$, and scarce education $(n=10)$ and awareness $(n=8)$.
According to respondents, the level of awareness/perception of $\mathrm{OH}$ amongst citizens/consumers their country is not high. Indeed, they could score from one (poor) to four (excellent), and the median score was 2.0 (Q1-Q3: 1.75-3.0). Details of the answers aggregated by countries are illustrated in Figure 9.

\section{Questionnaire Section 6-End of questionnaire, Including Comments/Remarks/Suggestions}

Only some respondents contributed to this last section, by adding a few comments, remarks and suggestions: four participants suggested that the questionnaire should have been less lengthy and more essential, with less detailed and clearer questions; three signaled that some questions and/or definition were not very clear (i.e., environmental toxicants and toxicant zoonoses); other three suggested that all questions should have the option "don't 


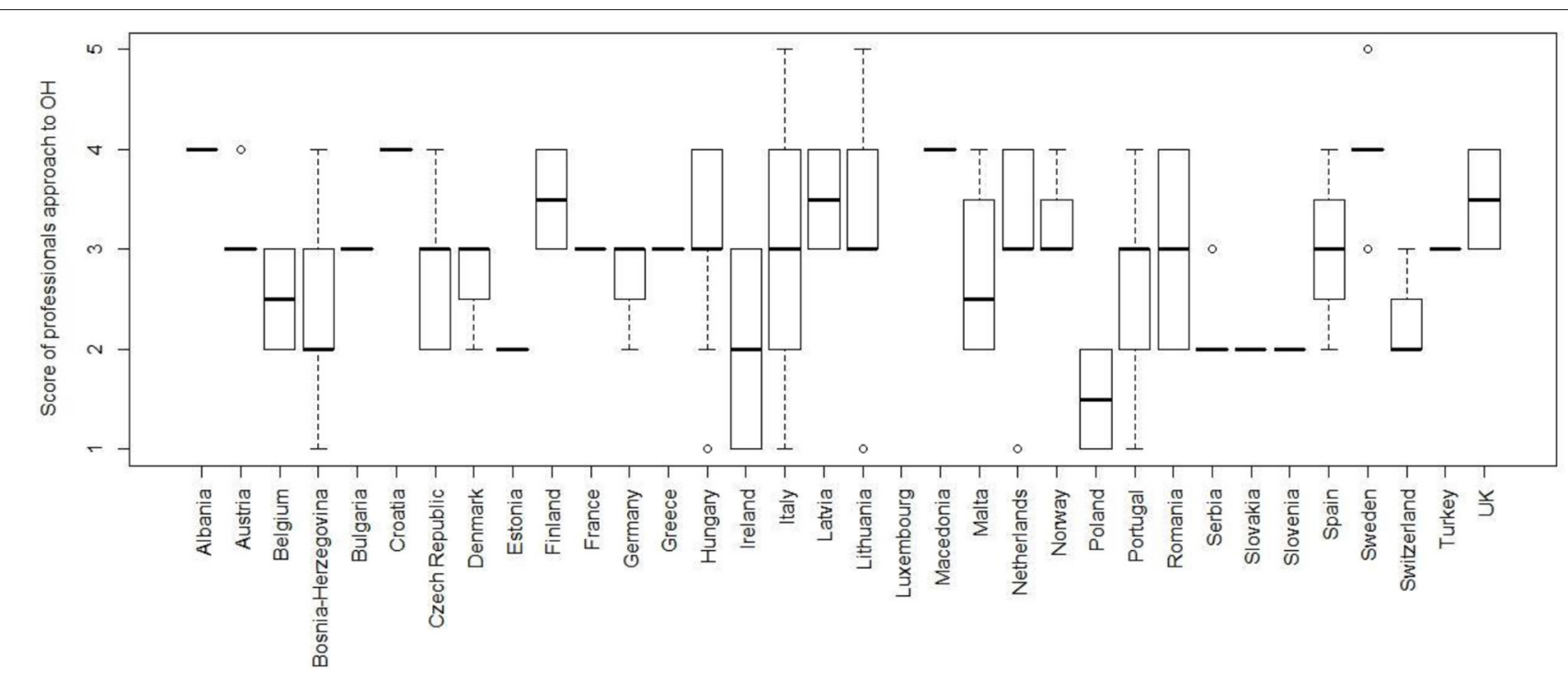

FIGURE 6 | Boxplot of the scores attributed by respondents on the implementation of the OH approach by professionals in their respective countries; scoring from one (poor) to five (excellent).

know/not sure about" (actually "don't know" was always available whenever applicable); a couple of respondents suggested that the text should have been revised by a English native speaker; two stated that the questionnaire was $\mathrm{OK}$ and no remarks/comments were needed; one reported that the questionnaire could not be saved in the process of filling in.

A few respondents included a set of comments/suggestions which deserve to be reported here [..."In view of the siloed mentality prevailing in the country, it is difficult to ascertain that the knowledge expressed in this questionnaire captures all the activities happening in other Ministries..", .... "the actions in favor of $\mathrm{OH}$ will have to continue their creative work in the Universities, both at undergraduate and graduate levels", ..."OH issues have to be emphasized at Academic level in each of the $3 \mathrm{OH}$ disciplines/components (i.e., Animal/HumanPublic/Environmental Health)", ... “include requirements for $\mathrm{OH}$ in health sector legislation, including specific budgeting of resources..", ... "Having projects managed by people having knowledge of more than one discipline and who are open to listen to all collaborators.."] and to be recalled/quoted in the discussion and conclusions.

\section{DISCUSSION}

Our survey aimed to provide an overview of the existence and the implementation of $\mathrm{OH}$ actions/initiatives in Europe and neighboring areas, of the type of institutions and disciplines involved in such initiatives, and on current limits to $\mathrm{OH}$ implementation according to professionals working in relevant fields (e.g., education, research, government).

Overall, the response rate $(51.3 \%)$ of our questionnaire survey falls within the range of the response rates of similar online questionnaires (22). In a study on response rate in organizational research, (23) reported an average response rate of $52.7 \%$ for studies that utilized data collected from individuals, while the average response rate for studies that utilized data collected from organizations was $35.7 \%$. However, few countries reached or exceeded the expected minimum number of questionnaires answered (nine per country).

The questionnaire design and distribution were managed such to reach an equal number of respondents from each of the three $\mathrm{OH}$ pillars/components, that is, animal health, humanpublic health and environmental health, evenly across countries, types of institutions and disciplines. However, there was a larger proportion of respondents from animal health, thereby skewing answers toward human and animal health with less consideration of ecosystem health and on collaborative and system aspects of $\mathrm{OH}$. This may be explained by the fact that the $\mathrm{OH}$ approach and the $\mathrm{OH}$ movement have been promoted strongly by animal health and public health, as documented in some of the most accredited and comprehensive reviews on the origin and development of $\mathrm{OH}(7,8)$. In addition, the larger number of respondents with a professional background in animal health/animal sciences, as well as the larger number of academics/researchers, seem to reflect the composition of $\mathrm{NEOH}$ and EurNegVec networks, who implemented the survey. As COST Actions are often research/academic networks, MC members and MC substitutes likely were better connected to academic and research colleagues than officials at Ministries/Directorates. The underrepresentation of nature/environment-related human health benefits and ecosystem health could be a limitation of this study and at the same time a reflection of the origins of $\mathrm{OH}$ and the networks of the participants of the two COST Actions. Potentially, more respondents from ecosystem fields could have been engaged with stronger wording around Ecohealth. 


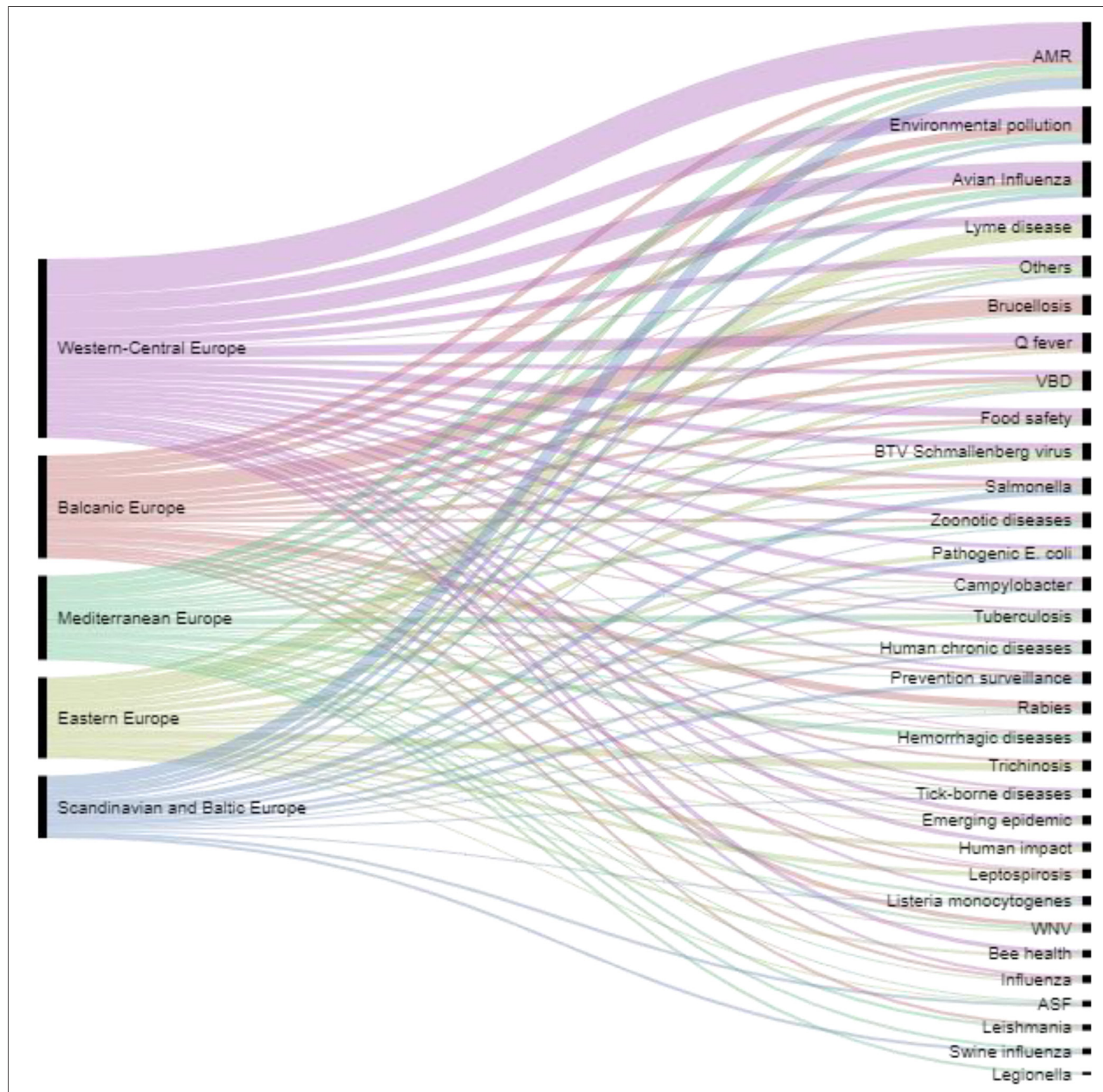

FIGURE 7 | Top environmental, animal and human health issues over the past 5 years cited by countries in the different regional areas.

Another limitation of our study is that data were collected in 2016-7 and therefore may not represent today's OH landscape in the countries surveyed. Nonetheless, it provides a baseline against which future studies of this type can be compared thereby contributing to documentation of how $\mathrm{OH}$ evolves in Europe and neighboring areas.

Although One Health was a familiar concept for the majority of respondents, only few were able to provide comprehensive definitions. Their answers demonstrated a traditional understanding of $\mathrm{OH}$ evolving around the linkages between "human" and "animal" health. The environmental health component was mentioned less frequently, which suggests that the three pillars/components of $\mathrm{OH}$ are overall not perceived as having equal importance. Similar differences amongst the three $\mathrm{OH}$ components seem to emerge from other questions, for example most of the respondents, who declared to be presently involved in $\mathrm{OH}$ initiatives, had a background in "Animal Sciences." Indeed, we registered 


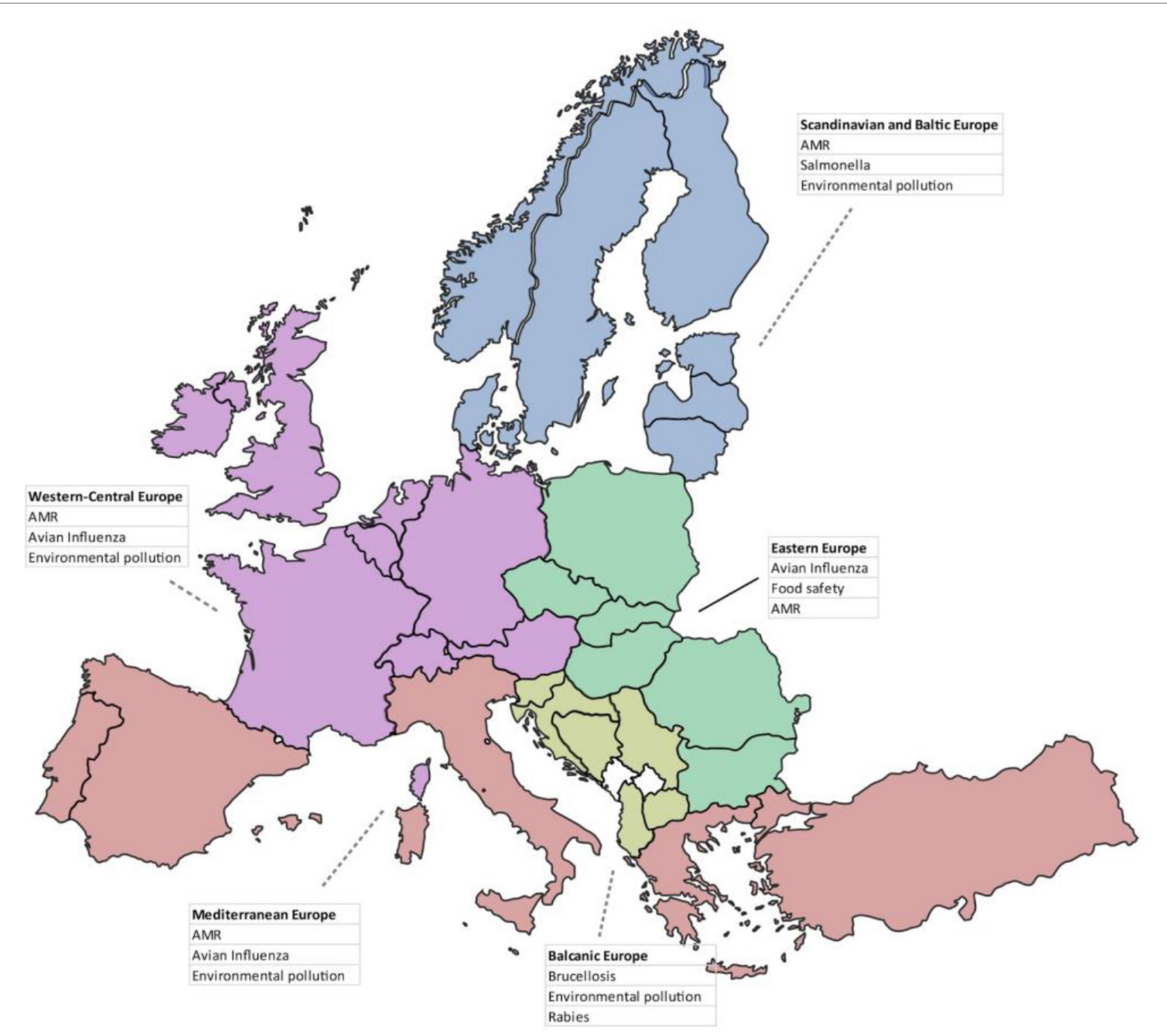

FIGURE 8 | Top three environmental, animal and human health issues over the past 5 years cited by respondents, divided by geographical regions.

a greater involvement in $\mathrm{OH}$ initiatives among Animal Sciences professionals, with $76.1 \%$ of respondents in this category being involved, vs. around half of respondents in "Public Health" and "Human Health" categories, and 37.5\% of "Environmental Sciences."

Only slightly more than half of the respondents involved in $\mathrm{OH}$ initiatives seemed to be personally engaged in $\mathrm{OH}$. Although adopting a $\mathrm{OH}$ approach for many is still a matter of a personal attitude and less of institutionalization, it seems that some steps toward official endorsement of $\mathrm{OH}$ are being taken, and this may constitute a move toward institutionalization of $\mathrm{OH}$-at least in the human and animal health fields. Another challenge emerging from our results is the low public awareness on $\mathrm{OH}$. This could be addressed through extension and information campaigns to give the general public access to $\mathrm{OH}$; and actually, such activities are being started. Existing $\mathrm{OH}$ initiatives mentioned by respondents related mainly to "classic zoonoses" (prevention, control, surveillance). This is probably because the majority of respondents belonged to institutions working in the animal and public health disciplines, and these disciplines were those that mainly endorse $\mathrm{OH}$. Other disciplinary sectors were less represented in our sample, so environmental problems, such as climate change, pollution, toxicants, socio-environmental aspects, were less mentioned.

In addition, we hypothesize that "chronic" environmental issues (i.e., contaminated agriculture soil and/or fallow land) are less visible and receive less attention both from the general 


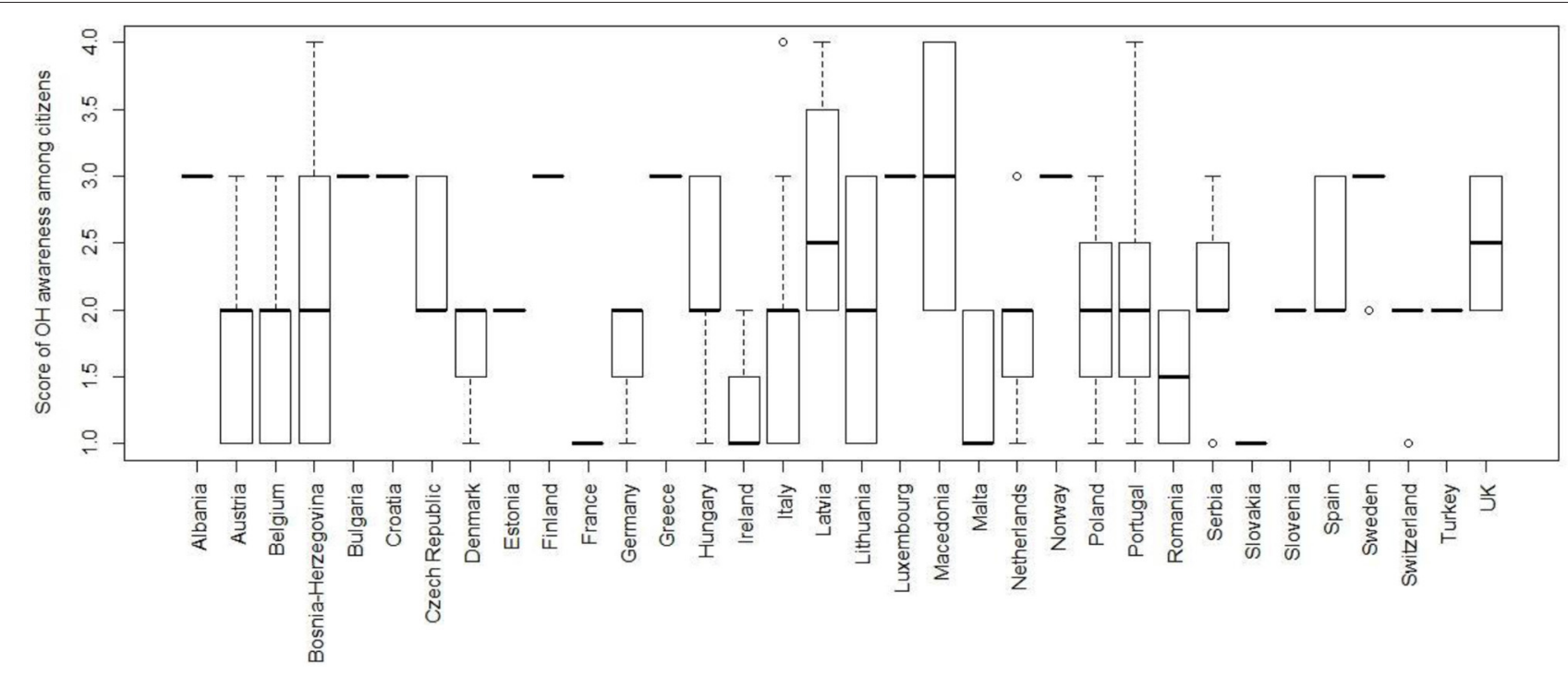

FIGURE 9 | Boxplot of the scores attributed by respondents to the level of awareness on OH in citizens in their respective countries; scoring from one (poor) to four (excellent).

public and health authorities/policy makers. Moreover, such environmental problems are usually more difficult to control and prevent.

The $\mathrm{OH}$ approach was adopted for zoonoses (surveillance and control), health education, AMR and food hygiene. Coincidentally, these are also common areas of the field of Veterinary Public Health and this brings up the question whether respondents differentiated between the two. Veterinary Public Health (i.e., the contribution of veterinary medicine to public health) has indeed gradually evolved in $\mathrm{OH}$ and in "ecosystem health" - that includes the whole ecosystem, and that considers health and ecosystems and their relevance for global health development (7).

According to the respondents, the most important advantages of $\mathrm{OH}$ are preventative measures such as early detection/rapid response, and effective disease control and/or biosecurity measures which actually put "prevention" at the highest rank. Lower scores were attributed to health improvement, knowledge/skills improvements, ecosystem and personal/social benefits, thus confirming a more "traditional" approach oriented toward disease surveillance and response, also suggesting a poor understanding of the environmental health component and still an apparent existing dichotomy between $\mathrm{OH}$ and Ecohealth. The fact that two thirds of respondents reported formal connections between veterinary and public health administrations (governmental institutions or services) is noteworthy. Remarkably, the highest "yes" frequency was registered among those respondents involved in Food Safety, Animal and Public/Human Health, while "No" answers prevailed amongst Environmental and Life Sciences persons, suggesting that respondents involved in the former disciplines seem to be more aware of such formal connections. Other respondents may be more aware of Ecohealth connections.
As pointed out by some authors (24-27), the two approaches, despite their apparent dichotomy, have a common ground and unifiying attributes. In fact, according to Zinsstag (7) both Ecohealth and One Health movements emphasize a holistic understanding of health beyond the purely biomedical and champion system thinking as a way of achieving a greater understanding of health problems; both approaches espouse inter- and trans-disciplinary research and collaborative participation. Literature in the field shows that the concepts continue to evolve and be discussed. For example, Lackey (28) promoted a challenging discussion on the values of ecosystem health, Antoine-Mussiaux et al. (29) provided an analysis on framing "nature" or the environment within the scientific communities involved, Harrison et al. (30) addressed the calls for convergence between $\mathrm{OH}$ and Ecohealth. Some areas already well-developed in Ecohealth (e.g., relationships between health and ecosystems or between health and sustainable development) have been growing in importance within the One Health movement. Each approach has its own strengths and -by working together- a greater impact in global health and sustainability may be achieved (25). In line with this view, NEOH has therefore established a new Network for Ecohealth and $\mathrm{OH}$ as a chapter of the Ecohealth International organization (https:// www.ecohealthinternational.org/regional-chapters/europe/).

Section 3, regarding zoonotic diseases, environmental health and AMR, provided interesting insights. More than $80 \%$ of the respondents reported an active cooperation in their countries between the Ministry of Health and the Ministry responsible for animal health, when dealing with zoonoses, also stating that there is an obligation to guarantee a reciprocal flux of information between Public Health and Veterinary Services. When respondents were asked to select which zoonotic diseases (from a list taken from Public Health England website) are 
or should be monitored and controlled by $\mathrm{MoH}$ and/or MoA, there was a convergence -with a few exceptions, that is, Ebola, ringworms, cysticercosis/taeniasis- in attributing the responsibilities to both Ministries. This could be related to the different organization of the Health System and Veterinary Services in the target countries.

Two questions were asked about environmental toxicants and it was requested to score the level of awareness by the public on "toxicant zoonoses" (zoonoses caused by exposure to environmental toxicants) and the quality of national plans for their prevention/monitoring. The percentage of respondents to these questions was not satisfactory; in fact, more than half of them stated that they were not competent in the field, thus suggesting that "non-traditional zoonoses" are generally less known or less taken into consideration.

While nearly half of the interviewees stated that their respective countries contribute to EU AMR surveillance with specific monitoring and research programs, there were some conflicting answers amongst respondents, that is, within the same country, some respondents stated that their country contribute to the EU AMR monitoring and others stated the contrary. However, the European surveillance systems/networks [e.g., EARS-Net (31)] and the international guidelines (16) are likely helping the full implementation of the National Action Plans (NAPs) to fight AMR.

In the section regarding the aspects limiting interdisciplinarity and intersectorality in $\mathrm{OH}$ (section 4), the "siloed approach" of disciplines was the most commonly mentioned limiting factor. Lack of resources, institutional and education limits were also cited. All these factors have long been recognized as barriers to moving toward $\mathrm{OH}(32)$.

When asked to score the level and opportunities for $\mathrm{OH}$ collaboration at different institutional and/or professional levels, the higher proportion of "good" and "excellent" scores were attributed to institutions involved in animal health surveillance/food security, and institutions involved in emergencies management. "Poor" scores prevailed as regards professional boards and university departments, but were attributed by a maximum of $26 \%$ of respondents, suggesting that in COST countries there is an overall positive perception about level and the opportunities for $\mathrm{OH}$ collaboration.

When asked to rate (one being "poor," and five "excellent") how well the $\mathrm{OH}$ approach is implemented by the professionals employed/engaged in Veterinary, Public and Environmental Health sectors, respondents gave a median score of 3 (Q13: 2-3). Although the great difference in the number of respondents per country makes it difficult to compare and comment the results, the authors consider such overall score (3) not much "encouraging." Professionals still need to do more efforts for implementing the $\mathrm{OH}$ approach in their respective countries. Alike, the answers on the existence of initiatives to establish/strengthen intersectoral collaboration, aimed at global advocacy of $\mathrm{OH}$ approach, yielded a not much promising picture: in fact, only $30 \%$ of the respondents are aware of such initiatives.

When asked to cite the top three environmental, animal and human health issues in their country over the past 5 years, most respondents cited AMR, avian influenza and environmental pollution. Such results seem consistent with the epidemiological situation at the time the questionnaire was circulated (201617). Indeed, in the period under review, AMR was -and actually still it is- capturing most attention by the international scientific community. Zoonotic avian flu was quoted as the second most important health topic as, since 2013, thousands of human cases and many deaths have been reported worldwide. Environmental pollution is considered by the respondents a "chronic" problem, quite often difficult to remediate and to solve, which induce several acute and long-term effects on human health and ecosystems.

The authors believe that if the questionnaire were to be administered nowadays, the top health issue would have certainly been the recent (and ongoing) COVID-19 pandemic.

Regional differences could also be observed, in particular between countries belonging to Balkan Europe and the other groups of countries: this is the only group where AMR was not included among the first three $\mathrm{OH}$ issues, while brucellosis and rabies were at the first and third position respectively. This reflects the endemic situation and the challenge posed to public health by these diseases in the Balkan countries (33-36). It is noteworthy that Salmonella falls in the top three issues in the Scandinavian and Baltic Europe: this foodborne pathogen, which has been the object of a strong and successful surveillance and control programme in these countries (37), is nonetheless considered as a top priority when public health is involved.

In this section, another important question/issue was about the level of awareness/perception of $\mathrm{OH}$ amongst citizens/consumers: the median score attributed by the respondents in their respective countries was only 2, and such overall data is not much "encouraging." This result not only highlights that respondents know that great work still needs to be done to raise public awareness about $\mathrm{OH}$, but also that we all, as members of research and academic institutions, have failed to engage citizens sufficiently. Though there were differences in the number of respondents per country, thus making it difficult to comment on the results, it is certainly crucial that academic and research Institutions, ministries, professional boards have to improve on dissemination, information and education activities, through public engagement and promotion activities on $\mathrm{OH}$ for general public and stakeholders.

The gaps on $\mathrm{OH}$ schemes cited were strictly related to the question posed in section 4 about factors limiting $\mathrm{OH}$ based on the respondents' personal experience. Although many professionals seem highly motivated to endorse the $\mathrm{OH}$ approach, barriers exist especially at the institutional level. In fact, interviewees underlined the lack of $\mathrm{OH}$ approach in institutions. The "siloed approach" of disciplines, scarce funding and education/awareness limits are other limits to intersectorality, resulting in poor networking, differing priorities and a lack of understanding between sectors.

Respondents from different sectors preferentially selected (prioritized) their own directorates/ministries when looking at the control and monitoring of zoonotic diseases, while actually in most countries, both $\mathrm{MoH}$ and $\mathrm{MoA}$ are engaged. In Italy, where Veterinary Services are under the Ministry of Health, such differences tend to be less evident. 
Despite the limitations described, this study provides an overview of perception and experiences in $\mathrm{OH}$ and $\mathrm{OH}$ initiatives in Europe, putting into evidence major gaps and challenges as well as opportunities to better apply $\mathrm{OH}$ approach. Identifying how initiatives are currently working and knowing their promoting and hindering factors has allowed insights into how improved education and incentives for those working in different areas of the field could change efficiency/effectiveness of $\mathrm{OH}$ implementation in years to come. As regards education, academia can play an important role to develop and implement a common $\mathrm{OH}$ curriculum to be used by the different European Universities to teach $\mathrm{OH}$ approach, strategies, and methods. Health and Environment Institutions/Ministries -together with the Academia, the professional boards, and NGOs- can promote awareness campaigns on the importance of $\mathrm{OH}$ approach with stakeholders and the general public at large. Scientists should make efforts to better communicate and share their research results on $\mathrm{OH}$ issues to the public and to politicians and policymakers: such process of sharing information and scientific-based opinions/recommendation would likely make scientists more listened to. The present COVID-19 pandemic -with its enormous toll of victims and socio-economic consequences- has probably greatly contributed to a better awareness of the importance of $\mathrm{OH}$, and -even more- Planetary Health.

Stakeholders, professional boards, the research world and academia, together with citizens must capitalize the momentum gained and use it as a trigger with politicians and decision makers -nationally and internationally to advance $\mathrm{OH}$ and related approaches.

\section{DATA AVAILABILITY STATEMENT}

The raw data supporting the conclusions of this article will be made available by the authors, without undue reservation.

\section{ETHICS STATEMENT}

An informed consent form was provided at the beginning of the questionnaire where the participants were advised that the questionnaire was anonymous and that, by completing and submitting it, they voluntarily agreed to participate. Ethical approval was sought and granted by the Clinical Research and Ethical Review Board at the Royal Veterinary College, grant holder of COST Action TD1404 NEOH (ref. prot. n. URN 2016 1554).

\section{AUTHOR CONTRIBUTIONS}

FC: conceptualization and design of the questionnaire survey, data cleaning and managing questionnaire answers, creation

\section{REFERENCES}

1. Rüegg SR, Nielsen LR, Buttigieg SC, Santa M, Aragrande M, Canali M, et al. A systems approach to evaluate $\mathrm{OH}$ initiatives. Front Vet Sci. (2018) 5:23. doi: $10.3389 /$ fvets. 2018.00023 of figures and tables, drafting and editing manuscript. LT: data cleaning and managing questionnaire answers, data management and analysis, creation of figures and tables, drafting and editing manuscript. SS: conceptualization and design of the questionnaire survey, collaboration in the survey distribution, drafting and editing manuscript. AB: data cleaning and managing questionnaire answers, collaboration in data analysis, collaboration in drafting manuscript. AM: general contribution in the study design, general supervision as EURNEGVEC chair, collaboration in the survey distribution. DM: general contribution in the study design, collaboration in the survey distribution. $\mathrm{BH}$ : conceptualization and design of the questionnaire survey, general supervision as $\mathrm{NEOH}$ chair, drafting and editing manuscript. DDM: conceptualization and design of the questionnaire survey, general coordination and supervision of the questionnaire distribution, managing questionnaire answers, drafting and editing manuscript. All authors: reviewing the final version of the manuscript.

\section{FUNDING}

This study was supported by the COST Actions TD1404 Network for Evaluation for One Health-NEOH and TD1303 European Network for Neglected Vectors and Vector-Borne InfectionsEURNEGVEC, and by Ministero dell'Istruzione, dell'Università e della Ricerca (MIUR) under the programme Dipartimenti di Eccellenza ex L.232/2016 to the Department of Veterinary Science, University of Turin.

\section{ACKNOWLEDGMENTS}

The authors would like to thank the MCs members and MC substitutes of $\mathrm{NEOH}$ and EURNEGVEC COST Actions for identifying, contacting the target respondents in their respective countries. The valuable contribution of all respondents who kindly answered the online questionnaire is highly acknowledged here: without their keen participation, this survey would not have been possible. Florence Morin, former EU FVO officer, is acknowledged for her suggestions and comments to the early version of the questionnaire, and Rebecca Morris, vet student at the RVC, for redacting a preliminary report on the initial answers to the questionnaire survey. Finally we thank Natalia Cediel, lecturer and researcher at Universidad de La Salle, Bogotà (Colombia) for her useful comments to the manuscript.

\section{SUPPLEMENTARY MATERIAL}

The Supplementary Material for this article can be found online at: https://www.frontiersin.org/articles/10.3389/fpubh. 2021.609949/full\#supplementary-material

2. Rüegg SR, Häsler B, Zinsstag J, editors. Integrated Approaches to HealthA Handbook for the Evaluation of $\mathrm{OH}$. Wageningen: Academic Publishers (2018). p. 256.

3. Yamada A, Kahn LH, Kaplan B, Monath TP, Woodall J, Conti L, editors. Confronting Emerging Zoonoses: The OH Paradigm. Cham: Springer (2014). 
4. Frazzoli C, Mantovani A. Toxicants exposures as novel zoonoses: reflections on sustainable development, food safety and veterinary public health. Zoonoses Public Health. (2010) 57:e136-42. doi: 10.1111/j.1863-2378.2009.01309.x

5. Patz JA, Hahn MB. Climate change and human health: a $\mathrm{OH}$ approach. Curr Top Microbiol Immunol. (2013) 366:141-71 141 doi: 10.1007/82_2012_274

6. Paternoster G, Tomassone L, Marchino M. WNV surveillance working groups of Emilia-Romagna, Lombardy, Piedmont regions, Vogler B, Balduzzi G, Favretto AR. Knowledge integration to evaluate $\mathrm{OH}$ - Process evaluation of West Nile virus integrated surveillance in northern Italy. NEOH Final Conference. Bologna, Italy (2018).

7. Zinsstag J, Schelling E, Waltner-Toews D, Tanner M. From “one medicine” to "one health" and systemic approaches to health and well-being. Prev Vet Med. (2011) 101:148-56. doi: 10.1016/j.prevetmed.2010.07.003

8. Zinsstag J, Schelling E, Waltner-Toews D, Whittaker M, Tanner M. One Health: The Theory and Practice of Integrated Health Approaches. Wallingford; Boston: CABI (2015).

9. Haxton E, Šinigoj Š, Rivière-Cinnamond A. The network for evaluation of one health: evidence-based added value of one health. Infect Ecol Epidemiology. (2015) 5:28164. doi: 10.3402/iee.v5.28164

10. Rüegg SR, McMahon BJ, Häsler B, Esposito R, Nielsen LR, Ifejika Speranza C, et al. A blueprint to evaluate One Health. Front Public Health. (2017) 5:20. doi: 10.3389/fpubh.2017.00020

11. Paternoster G, Tomassone L, Tamba M, Chiari M, Lavazza A, Piazzi M, et al. The degree of $\mathrm{OH}$ implementation in the West Nile virus integrated surveillance in northern Italy, 2016. Front Public Health. (2017) 5:236. doi: 10.3389/fpubh.2017.00236

12. Baum SE, Machalaba C, Daszak P, Salerno RH, Karesh WB. Evaluating One health: are we demonstrating effectiveness? One Health. (2017) 3:5-10. doi: 10.1016/j.onehlt.2016.10.004

13. Machalaba CC, Salerno RH, Barton Behravesh C, Benigno S, Berthe FC, Chungong $\mathrm{S}$, et al. Institutionalizing One Health: from assessment to action. Health Security. (2018) 16:S-37. doi: 10.1089/hs.2018.0064

14. Stephen C, Karesh WB. Is OH delivering results? Introduction. Rev Sci Tech. (2014) 33:375-92. doi: 10.20506/rst.33.2.2301

15. World Bank. One Health: Operational Framework for Strengthening, Human, Animal, and Environmental Public Health Systems at Their Interface. 1st ed. Washington, DC: World Bank (2018).

16. WHO/FAO/OIE. Antimicrobial Resistance-A Manual for Developing National Action Plans. Geneva; Paris; Rome: WHO/FAO/OIE Publishers. p. 32 .

17. Khan MS, Rothman-Ostrow P, Spencer J, Hasan N, Sabirovic M, Rahman-Shepherd A, et al. The growth and strategic functioning of $\mathrm{OH}$ networks: a systematic analysis. Lancet Planet Health. (2018) 2:e264-73. doi: 10.1016/S2542-5196(18)30084-6

18. Saleh A, Bista K. Examining factors impacting online survey response rates in educational research: perceptions of graduate students. J Multidiscip Evaluation. (2017) 13:63-73.

19. R Core Team. R: A Language and Environment for Statistical Computing. Vienna, Austria: R Foundation for Statistical Computing, (2019).

20. Destoumieux-Garzón D, Mavingui P, Boëtsch G, Boissier J, Darriet F, Duboz P, et al. The OH concept: 10 years old and a long road ahead. Front Vet Sci. (2018) 5:14. doi: 10.3389/fvets.2018.00014

21. Häsler B, Cornelsen L, Bennani H, Rushton J. A review of the metrics for $\mathrm{OH}$ benefits. Rev Sci Tech. (2014) 33:453-64. doi: 10.20506/rst.33.2.2294

22. Millar MM, Dillman DA. Improving response to web and mixed-mode surveys. Public Opinion Quarterly. (2011) 75:249-69. doi: 10.1093/poq/nfr003
23. Baruch Y., Holtom B. C. (2008). Survey response rate levels and trends in organizational research. Human relations. 61:1139-1160. doi: $10.1177 / 0018726708094863$

24. $\mathrm{Mi}$ E, Mi E, Jeggo M. Where to now for $\mathrm{OH}$ and eco-health? EcoHealth. (2016) 13:12-7. doi: 10.1007/s10393-016-1112-1

25. Zinsstag J. Convergence of eco-health and one health. EcoHealth. (2012) 9:371-3. doi: 10.1007/s10393-013-0812-Z

26. Zinsstag J. OH EcoHealth 2016: welcome from the president of theInternational Association for Ecology and Health. EcoHealth. (2016) 13:613-4. doi: 10.1007/s10393-016-1180-2

27. Lerner H, Berg C. A comparison of three holistic approaches to health: one health, ecohealth, and planetary health. Front Vet Sci. (2017) 4:163. doi: $10.3389 /$ fvets. 2017.00163

28. Lackey RT. Values, policy, and ecosystem health. BioScience. (2001) 51:437-4 doi: 10.1641/0006-3568(2001)051(0437:VPAEH)2.0.CO;2

29. Antoine-Moussiaux N, Janssens de Bisthoven L, Leyens S, Assmuth T, Keune $\mathrm{H}$, Zinsstag, J, et al. The good, the bad and the ugly: framing debates on nature in a One Health community. Sustain Sci. (2019) 14:1729-38. doi: 10.1007/s11625-019-00674-z

30. Harrison S, Kivuti-Bitok L, Macmillan A, Priest P. EcoHealth and One Health: a theory-focused review in response to calls for convergence. Environ Int. (2019) 132:105058. doi: 10.1016/j.envint.2019.105058

31. European Antimicrobial Resistance Surveillance Network (EARS-Net). Available online at: https://www.ecdc.europa.eu/en/about-us/partnershipsand-networks/disease-and-laboratory-networks/ears-net

32. World Bank Group. People, Pathogens, and our Planet-Volume One: Towards a $\mathrm{OH}$ Approach for Controlling Zoonotic Diseases. Washington, DC: World Bank Group (2010).

33. Rossetti CA, Arenas-Gamboa AM, Maurizio E. Caprine brucellosis: a historically neglected disease with significant impact on public health. PLoS Negl Trop Dis. (2017) 11:e0005692. doi: 10.1371/journal.pntd.0005692

34. Bosilkovski M, Stojanov A, Stevanovic M, Karadzovski Z, Krstevski K. Impact of measures to control brucellosis on disease characteristics in humans: experience from an endemic region in the Balkans. Infect Dis. (2018) 50:340-5. doi: 10.1080/23744235.2017.1407037

35. Buttigieg SC, Savic S, Cauchi D, Lautier E, Canali M, Aragrande M. Brucellosis control in Malta and Serbia: a OH evaluation. Front Vet Sci. (2018) 5:147. doi: 10.3389/fvets.2018.00147

36. Henning J, Giorgi E, Magalhães RS, Tizzani P, Viviani P, Pejovic N, et al. Factors influencing the success of aerial rabies vaccination of foxes. Scientific Rep. (2017) 7:1-9. doi: 10.1038/s41598-017-14615-2

37. Houe H, Nielsen SS, Nielsen LR, Ethelberg S, Mølbak K. Opportunities for improved disease surveillance and control by use of integrated data on animal and human health. Front Vet Sci. (2019) 6:301. doi: 10.3389/fvets.2019. 00301

Conflict of Interest: The authors declare that the research was conducted in the absence of any commercial or financial relationships that could be construed as a potential conflict of interest.

Copyright (C) 2021 Chiesa, Tomassone, Savic, Bellato, Mihalca, Modry, Häsler and De Meneghi. This is an open-access article distributed under the terms of the Creative Commons Attribution License (CC BY). The use, distribution or reproduction in other forums is permitted, provided the original author(s) and the copyright owner(s) are credited and that the original publication in this journal is cited, in accordance with accepted academic practice. No use, distribution or reproduction is permitted which does not comply with these terms. 